\title{
Research and Application of Quantitative Evaluation Method based on Product Quality Characteristics
}

\author{
Wangming Jin ${ }^{\text {a }}$, Zhulin Wang \\ China Nuclear Power Operation Technology Corporation CNPO LTD, Wuhan 430223, China \\ a Jinwm@cnnc.com.cn
}

\begin{abstract}
The current situation of enterprise product quality evaluation is analyzed in this paper, and a set of quantitative evaluation methods based on product quality characteristics in response to the existing problems is proposed. The specific evaluation process is defined, and the steps such as determining product category, identifying quality characteristics, developing evaluation Indicators, carrying out evaluation work, overall quality evaluation and application of evaluation results are introduced in detail. Practice has proved that this method can scientifically analyze and evaluate the individual products and overall quality level of enterprises, can be applied in enterprise quality assessment, quality improvement and macro decision-making, and effectively improve the quality management ability of enterprises.
\end{abstract}

Keywords: Quality Characteristics; Product Inherent Quality; Quantitative Evaluation; Application.

\section{Introduction}

At present, the basic mission of an enterprise is to provide the market with high-quality products that meet customer needs. Product quality is the lifeblood of an enterprise. If the quality of an enterprise's products is poor, the enterprise will eventually lose the basis for survival. How to effectively evaluate product quality, identify and improve the weak links in product quality, and meet the needs of enterprise internal control, government administrative supervision and consumers is directly related to the success or failure of the enterprise.

Product quality is usually comprehensively evaluated from three aspects: inherent quality, perceived quality, and loss quality. The inherent quality of the product is the basis of product quality and will directly affect the perceived quality and loss quality. In the current situation, the product qualification rate is generally used to evaluate the inherent quality of the product, and the evaluation method is too extensive. In response to this problem, this paper proposes a quantitative evaluation method based on quality characteristics, which can scientifically analyze and evaluate the quality of enterprise products, and can be applied in enterprise quality assessment, quality improvement, and macro decision-making.

\section{Current Status and Existing Problems of Product Quality Evaluation}

\subsection{Current Status of Product Quality Evaluation}

The concept of product quality has undergone nearly a century of development, evolution and improvement, and has formed numerous theoretical viewpoints and practical experiences. The scientific definition of the conceptual model and dimensional composition of product quality is the primary prerequisite for building a complete evaluation indicator system to measure the overall quality level of products. Based on the in-depth analysis of existing theories, product quality should be comprehensively evaluated from three aspects: inherent quality, perceived quality and loss quality. The definitions, purpose and evaluation indicators of the three items are shown in the following table:

\subsection{Problems in Product Quality Evaluation}

It can be seen from the above definition that the inherent quality of a product is the basis of product quality, which will directly affect the subsequent perceived quality and loss of quality. In the current situation, if only the product qualification rate is used to evaluate the inherent quality of the product, 
the evaluation method is too extensive, which is not conducive for enterprises to understand and evaluate the quality level of their own products, to discover the problems existing in product quality in time, and to seek ways to improve product quality.

Table 1. Current status of product quality evaluation

\begin{tabular}{|c|c|c|c|c|}
\hline No. & Item & definition & purpose & $\begin{array}{l}\text { evaluation } \\
\text { indicator }\end{array}$ \\
\hline 1 & $\begin{array}{c}\text { inherent } \\
\text { quality }\end{array}$ & $\begin{array}{l}\text { After the product is produced, the } \\
\text { degree of conformity between its "set } \\
\text { of characteristics" and related laws, } \\
\text { regulations, standards and design } \\
\text { purposes. The lower the degree of } \\
\text { deviation, the better the quality of the } \\
\text { product, and vice versa. }\end{array}$ & $\begin{array}{l}\text { From the perspective of } \\
\text { government quality supervision } \\
\text { and enterprise's quality inspection, } \\
\text { it reflects the government and } \\
\text { enterprise's product quality } \\
\text { expectations and the conformity } \\
\text { characteristics of product quality }\end{array}$ & $\begin{array}{l}\text { Product } \\
\text { qualification } \\
\text { rate }\end{array}$ \\
\hline 2 & $\begin{array}{l}\text { perceived } \\
\text { quality }\end{array}$ & $\begin{array}{l}\text { In the process of product } \\
\text { consumption, the consumers compare } \\
\text { between the basic quality and the } \\
\text { expected quality. If the basic quality } \\
\text { is higher than the consumer's } \\
\text { expected quality, the excess quality is } \\
\text { a positive value. }\end{array}$ & $\begin{array}{l}\text { Starting from the consumer's } \\
\text { experience in the consumption } \\
\text { process, it reflects consumers' } \\
\text { subjective feelings about product } \\
\text { quality, and reflects the } \\
\text { adaptability characteristics of } \\
\text { product quality }\end{array}$ & $\begin{array}{l}\text { Customer } \\
\text { satisfaction } \\
\text { rate }\end{array}$ \\
\hline 3 & $\begin{array}{l}\text { loss } \\
\text { quality }\end{array}$ & $\begin{array}{l}\text { Losses caused by functional } \\
\text { fluctuations or their own defects after } \\
\text { the product leaves the factory, } \\
\text { including tangible losses (material, } \\
\text { property, etc.) and intangible losses. }\end{array}$ & $\begin{array}{l}\text { From the economic and social } \\
\text { perspective, it reflects the social } \\
\text { and economic losses caused by } \\
\text { the products, and reflects the } \\
\text { external characteristics of product } \\
\text { quality. }\end{array}$ & $\begin{array}{l}\text { Quality loss } \\
\text { rate }\end{array}$ \\
\hline
\end{tabular}

In the ISO9000 standard, it defines quality characteristics as inherent attributes of objects related to requirements. According to this definition, to study the quality of a product, it is necessary to understand its quality characteristics. Determining quality characteristics is the process of transforming specific requirements into qualitative or quantitative standards or indicators. Translating quality characteristics into quality indicators and establishing a fixed evaluation system can carry out quality evaluation more effectively, which is also the core of product quality evaluation.

\section{Product Quality Evaluation Process Analysis}

\subsection{Overall Evaluation Process}

When carrying out quality evaluation work through product quality characteristics, it usually includes six steps, which is determining product categories, identifying quality characteristics, formulating evaluation indicators, carrying out evaluation work, overall quality evaluation, and application of evaluation results.

\subsection{Determining Product Categories}

In GB/T19000-2015 "Quality Management System Fundamentals and Terminology", the output of the organization is distinguished into two categories: products and services. The definition of a product is the output produced by the organization without any transaction between the organization and the customer, and service refers to the output of the organization where at least one activity must be carried out between the organization and the customer. The products include hardware, process materials and software. Software consists of information, which is an intangible product, and can exist in the form of drawings, reports, or programs. Hardware is usually a tangible product, and its quantity has the characteristic of counting. Processed materials are usually tangible products whose 
quantities have continuous characteristics. Hardware and process materials are often referred to as goods.

GB/T19000-2015 only proposes the basic classification of products. In actual production, in order to better evaluate product quality, the organization can further subdivide it according to the actual situation. For example, a technical service company of nuclear power plant (NPP) mainly provides technical services, technical support and the supply of various tools and software systems to nuclear power plants. After detailed analysis, the product classification is determined as shown in the following Table:

Table 2. Nuclear power supplier's product classification

\begin{tabular}{|c|c|c|}
\hline No. & Basic category & Product segmentation \\
\hline 1 & Hardware & In-service inspection equipment, maintenance equipment, training equipment \\
\hline 2 & Software & Computer programs, design drawings, technical reports \\
\hline 3 & Service & NPP in-service inspection, NPP maintenance, test and verification \\
\hline
\end{tabular}

\subsection{Identifying Quality Characteristics}

Identifying product quality characteristics is the process of transforming specific requirements into qualitative or quantitative standards or indicators. This is the core of product quality evaluation. For different product categories, such as hardware products, software products, process materials, they have different forms of quality characteristics. According to the inherent attributes of various products, the quality characteristics of the products are shown in the following Table:

Table 3. Product quality characteristics

\begin{tabular}{|c|c|c|}
\hline No. & Product & Quality characteristics \\
\hline 1 & Hardware & Performance, life, reliability, safety, economy \\
\hline 2 & Software & Functionality, reliability, ease of use, efficiency, maintainability, portability \\
\hline 3 & Process material & Physical properties, chemical properties, mechanical properties, appearance \\
\hline 4 & Service & Functionality, timeliness, safety, economy, comfort, civility \\
\hline
\end{tabular}

In addition, according to the impact on product suitability and economic loss, the importance of different product characteristics is also different. They usually can be divided into key characteristics, important characteristics and general characteristics, whose specific definition is as follows:

key characteristics: If a failure occurs, the main functions of the product will be lost, which will seriously affect the performance of the product and reduce the life of the product, or cause pollution to the environment that violates laws and regulations.

Important characteristics: If a failure occurs, it will affect the general performance and life of the product, and the user may complain for that.

General characteristics: If a failure occurs, it will have little effect on the product, performance and life, and will not cause complaints from the user.

\subsection{Formulating Evaluation Indicators}

The core tasks of product quality evaluation is to Transform quality characteristics into quality indicators and establish a product quality evaluation system. In this process, the following principles should be obeyed:

In order to realize the refined management of product quality evaluation, quantitative evaluation methods should be adopted to decompose the overall quality evaluation into various evaluation indicators according to 100 points;

In the process of selecting quality characteristics as evaluation indicators, the differences of various indicators should be fully considered, the key indicators, important indicators and general indicators of the product should be identified, and the weight design and ratio should be treated differently; 
In order to realize the comprehensive quality evaluation of various types of products, the evaluation indicator system of different products must have a reasonable hierarchical structure. They should be coordinated and unified to more comprehensively reflect the basic quality status of various products;

Product quality indicators should be formulated by technical personnel who are familiar with the product; for specific technical indicators, relevant requirements can be given based on domestic and international standards and industry experience;

For companies with more product categories, product quality indicators should mainly target hardware products that have mature technology, have been produced/supplied many times, and have certain industry comparability.

The paper takes the above-mentioned nuclear power plant supplier as an example to introduce the establishment of the enterprise's product evaluation indicator system. The enterprise's products are divided into three categories: hardware, software and services. In the process of formulating hardware product quality indicators, product functions and performance are taken as key indicators, processing quality control and the implementation of the "six characteristics" requirements are taken as important indicators, and appearance and documentation are taken as general indicators. The specific evaluation system design is shown in the Table below.

Table 4. Quality characteristics of hardware products

\begin{tabular}{|c|c|c|c|}
\hline No. & Quality indicator & Score & Evaluation criterion \\
\hline 1. & $\begin{array}{l}\text { functional integrity and } \\
\text { performance compliance }\end{array}$ & 40 & $\begin{array}{l}\text { Meet the product function and performance requirements of the } \\
\text { contract and technical specifications. ( } 5 \text { points deducted for } \\
\text { finding a problem) }\end{array}$ \\
\hline 2. & $\begin{array}{l}\text { Implementation of "six } \\
\text { characteristics" measures }\end{array}$ & 20 & $\begin{array}{c}\text { Provide relevant evidence of reliability, maintainability, safety and } \\
\text { environmental adaptability. ( } 5 \text { points deducted for finding a } \\
\text { problem) }\end{array}$ \\
\hline 3. & $\begin{array}{l}\text { Material, processing size, } \\
\text { assembly and surface } \\
\text { treatment }\end{array}$ & 20 & $\begin{array}{l}\text { Whether the material, processing size, assembly and surface } \\
\text { treatment of parts meet the requirements of drawings and technical } \\
\text { specifications. ( } 3 \text { points deducted for finding a problem) }\end{array}$ \\
\hline 4. & Appearance & 10 & $\begin{array}{l}\text { The appearance of the product is intact, beautiful and free of } \\
\text { defects. ( } 2 \text { points deducted for finding a problem) }\end{array}$ \\
\hline 5. & $\begin{array}{l}\text { Documentation normative } \\
\text { and complete }\end{array}$ & 10 & $\begin{array}{l}\text { The documents and records in the product design and } \\
\text { development process are complete, the content is accurate, the } \\
\text { format is standardized, and the signature is complete. ( } 2 \text { points } \\
\text { deducted if a problem is found) }\end{array}$ \\
\hline 6. & $\begin{array}{l}\text { Exceed expectations (plus } \\
\text { points) }\end{array}$ & 5 & $\begin{array}{c}\text { On the basis of technical requirements, there are some } \\
\text { improvements and innovations that has been recognized by the } \\
\text { inspectors. }\end{array}$ \\
\hline
\end{tabular}

In the process of formulating software product quality indicators, product functions and performance are taken as key indicators, and other indicators are used as general indicators. The specific evaluation system design is shown in the Table 5.

\subsection{Carrying out Quality Evaluation}

After the evaluation indicators are formulated, the enterprise can carry out specific evaluation. Since product quality evaluation involves multiple departments such as design, production, and inspection, in order to ensure that the collected data sources are reliable and the evaluation results are true and effective, the enterprise should set up a centralized responsible department at the organizational level, and formulate procedures to specify the development of specific tasks, such as the requirements for product data collection, the department responsible for the evaluation, the evaluation cycle, and the application of the evaluation results. It is recommended to improve the efficiency of product quality evaluation by means of information technology. 
Table 5. Quality characteristics of software products

\begin{tabular}{|c|c|c|c|}
\hline No. & Quality indicator & Score & Evaluation criterion \\
\hline 1. & $\begin{array}{l}\text { functional integrity and } \\
\text { performance } \\
\text { compliance }\end{array}$ & 40 & $\begin{array}{l}\text { Meet the product function and performance requirements of the } \\
\text { contract and technical specifications. (5 points deducted for } \\
\text { finding a problem) }\end{array}$ \\
\hline 2. & Ease of use & 10 & $\begin{array}{l}\text { The user interface is friendly, the style is unified, and the } \\
\text { operation is convenient. It is suitable for all users of the system. } \\
\text { ( } 2 \text { points deducted if a problem is found) }\end{array}$ \\
\hline 3. & reliability & 10 & $\begin{array}{c}\text { The software runs reliably in a stable state. (2 points deducted if a } \\
\text { problem is found) }\end{array}$ \\
\hline 4. & safety & 10 & $\begin{array}{l}\text { The software provides services to authorized users while } \\
\text { preventing unauthorized operations from unauthorized users. (No } \\
\text { prevent, } 10 \text { points deducted) }\end{array}$ \\
\hline 5. & Maintainability & 10 & $\begin{array}{c}\text { The software is easy to understand, easy to test, and easy to } \\
\text { modify when the environment changes or errors occur. ( } 2 \text { points } \\
\text { deducted if a problem is found) }\end{array}$ \\
\hline 6. & portability & 10 & $\begin{array}{l}\text { The software can be easily transplanted to different operating } \\
\text { environments. ( } 2 \text { points deducted if a problem is found) }\end{array}$ \\
\hline 7. & $\begin{array}{l}\text { Documentation } \\
\text { normative and } \\
\text { complete }\end{array}$ & 10 & $\begin{array}{l}\text { The documents and records in the product design and } \\
\text { development process are complete, the content is accurate, the } \\
\text { format is standardized, and the signature is complete. ( } 2 \text { points } \\
\text { deducted if a problem is found) }\end{array}$ \\
\hline 8. & $\begin{array}{l}\text { Exceed expectations } \\
\quad \text { (plus points) }\end{array}$ & 5 & $\begin{array}{l}\text { On the basis of technical requirements, there are some } \\
\text { improvements and innovations that has been recognized by the } \\
\text { inspectors. }\end{array}$ \\
\hline
\end{tabular}

In addition, after the product quality score is obtained, the product quality grades can be divided, which can usually be classified into four grades: top-quality product, first-class product, qualified product and unqualified product. The definitions are as follows:

1. Top-quality products $(90<$ evaluation score $<100)$ : The product quality represents the most advanced quality level of the company, and various indicators are well controlled.

2. First-class products $(80<$ evaluation score $<90)$ : The product quality level has reached the company's high-quality level, and most of the quality indicators are well controlled.

3. Qualified product $(60<$ evaluation score $<80)$ : The product quality level has reached the company's qualified level, and some quality index control problems have occurred.

4. Unqualified product (evaluation score $<60$ ): If the product quality is unqualified, the unqualified report should be started immediately to correct the quality problem in time.

\subsection{Overall Quality Evaluation}

When the quality levels of various products are obtained, the overall quality of the enterprise can be evaluated. Because the status of unqualified products can be measured by the product qualification rate. Therefore, the overall quality of the company is only for qualified products. The formula for calculating the product quality grade rate of an enterprise is shown below:

$$
G=\frac{\alpha_{1} \times P_{1}+\alpha_{2} \times P_{2}+\alpha_{3} \times P_{3}}{P} \times 100 \%
$$

Notes:

(1) $\alpha 1, \alpha 2$, and $\alpha 3$ are the coefficients of top-quality, first-class and qualified products, respectively. In the current industrial product quality index system, it is uniformly stipulated that $\alpha 1=1.0, \alpha 2=0.8$, and $\alpha 3=0.6$.

(2) P1, P2, and P3 are the output values of top-quality, first-class, and qualified products during the reporting period. 
(3) $\mathrm{P}$ is the total output value of the product during the evaluation period.

After the results are calculated, the overall quality level of the company can be evaluated according to the following Table:

Table 6. Quality level of the overall product

\begin{tabular}{|c|c|c|}
\hline No. & Calculation result & Quality level \\
\hline 1 & $\mathrm{G}=60 \%$ & The overall product of the enterprise is at a qualified level \\
\hline 2 & $60 \%<\mathrm{G}<80 \%$ & The overall product of the enterprise is between the qualified level and the first-class \\
level.
\end{tabular}

\section{Application and Precautions of Product Quality Evaluation}

When an enterprise establishes a product quality evaluation system in accordance with the above process, it can effectively improve its quality management level, and the evaluation results can be applied in the following aspects:

It can be used to evaluate the product quality of the team/department. According to the product quality score, the quality level of the product can be scientifically evaluated, so as to make a scientific evaluation of the work quality of the corresponding team/department.

It can be used as input for product quality improvement. According to the product quality score, it can identify weaknesses in product quality in time and make improvements so as to avoid customer complaints and quality loss.

It can be used for the macro decision-making of enterprises. Through the quality evaluation and overall quality evaluation of various products, horizontal and vertical comparison, analysis and benchmarking can be carried out at the industry level, and the product quality status of the enterprise can be understood in time, which provide basis for macro decision-making.

Due to the complexity of the product quality evaluation work, the evaluation implementation is also kind of subjective, and enterprises also need a certain amount of resources to carry out related work. In order to ensure that the evaluation results are objective and effective, and can truly reflect the quality level of the enterprise, the following matters should be paid attention to during the process:

The rationality of product classification should be ensured. In addition to the basic classification of products proposed in the reference standard, enterprises need to fully consider the actual situation of their products and combine the industry conditions to further subdivide the products, such as distinguishing standard products and non-standard products;

The product indicators should be scientific and reasonable. Transforming quality characteristics into quality indicators is the core work of product quality evaluation. In this process, the core and key performance indicators of the product should be fully identified, and reasonable weights should be set. At the same time, the indicators should not be too complicated.

The evaluation data should be true and valid. Due to the complexity of the product manufacturing process, in order to ensure that the data collected is reliable, the company should set up fixed evaluators to ensure that the collection of quality data is considered from the overall life cycle of the product to ensure that the data is true and effective.

\section{Summary}

This paper analyzes the current status of product quality evaluation, and proposes a set of inherent product quality evaluation methods based on quality characteristics in view of the current problems in product quality evaluation, which can scientifically analyze and evaluate the quality level of a certain type of product and the overall enterprise Product quality level. Then, horizontal and vertical 
comparison, analysis and benchmarking within the enterprise and the industry level can be carried out timely to understand the company's product quality status and provide a basis for the company's macro decision-making.

\section{References}

[1] Yongwei Li, Hu Lei. Research on process optimization of nuclear power inspection and maintenance tool development project [J]. Project Management Technology, 2016, (9): 105-109.

[2] Bing Zhang. Discussion on the relationship between quality inspection and quality management system [J]. Heilongjiang Science and Technology Information, 2011, (9): 133.

[3] Xiaoping Shi, Daoyi Zhang, Cheng Ping. Quality inspection and control of developed products [J]. Nuclear Standard Metrology and Quality, 2009 (1): 52-55. 